\title{
Distribuição do caranguejo Hepatus pudibundus (Herbst, 1785) (Crustacea, Decapoda, Brachyura) na Enseada da Fortaleza, Ubatuba (SP), Brasil
}

\section{Fernando Luis Mcdina MANTELATTO ${ }^{1 *}$; Adilson FRANSOZO $^{2^{*}}$ \& Maria Lúcia NEGREIROS-FRANSOZO ${ }^{2 *}$}

${ }^{1}$ Departamento de Biologia, FFCLRP, Universidade de Sâo Paulo

(Campus de Ribcirāo Preto, 14040-901, Ribeirāo Preto, SP, Brasil)

${ }^{2}$ Instituto de Biociências, Departamento de Zoologia, UNESP

(Campus de Botucatu, Caixa Postal 502, 18618-000, Botucatu, SP, Brasil)

\begin{abstract}
- Abstract: The goal of this work is to characterize the distribution of the calico crab Hepatus pudibundus (HERBST, 1785) in Fortaleza Bay, Ubatuba (SP), analised as a function of several environmental factors. Total of 405 specimens were collected in seven radials in the bay. Hepatus pudibundus occurred in all radials with heterogeneous abundance and its distribution was associated to several factors, mainly the texture and organic of sediment.

- Resumo: Estudos acurados sobre a fauna macrobêntica e sua relação com o ambiente são importantes para a análise da funçāo e estrutura de áreas litorâneas. A finalidade deste trabalho é caracterizar uma populaçāo do caranguejo Hepatus pudibundus na Enseada de Fortaleza, Ubatuba (SP), enfocando sua distribuiçāo espacial, relacionado-a aos fatores físico-químicos (profundidade, temperatura, oxigênio dissolvido, salinidade, textura e teor de matéria orgânica do sedimento). Com um barco de pesca, equipado com duas redes de arrasto para camarāo (tipo "otter--trawl"), procedeu-se a coleta dos caranguejos, efetuada mensalmente, no período de novembro/1988 a outubro/1989, em sete radiais de $1 \mathrm{Km}$ cada. Foram obtidos 405 espécimes, mostrando uma abundância heterogênea. A radial IV apresentou o menor número de indivíduos, o que pode ser explicado pelas condiçōes físicas do sedimento (bastante compactado devido a porcentagem de silte + argila) e da água (baixa salinidade). Em função dos resultados obtidos, ha fortes indícios para concluir que a Enseada da Fortaleza reúne condiçōes favoráveis à procriaçāo e desenvolvimento de $H$. pudibundus. Tais condiçōes levam a crer que pequenas variaçōes nos fatores bióticos e abióticos não são suficientes para alterar o padrão de distribuição desta espécic, intimamente relacionada à textura e teor de matéria orgânica do sedimento.
\end{abstract}

- Descriptors: Brachyura, Distribution, Environmental factors, Hepatus pudibundus, Ubatuba, São Paulo, Brazil.

- Descritores: Brachyura, Distribuição, Fatores ambientais, Hepatus pudibundus, Ubatuba, São Paulo, Brasil.

\section{Introdução}

O relevo da região litorânca do Estado de São Paulo é caracterizado por uma conformação topográfica que

(*) NEBECC (Núcleo de Estudos em Biologia, Fcologia e Cultivo de Crustáceos) evidencia esporōes terminais da Serra do Mar (Ab'Saber, 1955; Suguio \& Martin, 1978). Esta geomorfologia se reflete em um litoral extremamente recortado, com enseadas e baías, onde encontramos ambientes com limites internos muito irregulares, propícios ao estabclecimento de faunas marinhas particulares, estabclecidas $\mathrm{cm}$ funçāo 
das características e necessidades ccológicas de cada espécie.

A distribuiçāo destes organismos marinhos pode ser influenciada pela ação de certos fatores ambientais, os quais podem agir, determinando uma ocupação em ambientes variados, ou entāo, restringir a ocupaçāo em áreas mais localizadas. Desta forma, cada organismo ocupa um determinado espago onde as condiçôes do meio físico e biótico, são pelo menos, as mínimas necessárias para propiciar sua sobreviyência.

Em estudos sobre populaçōes naturais, observa-se uma tendência para ocorrência de uma distribuição espacial dos organismos, determinando padrōes evidentes, formados geralmente por agregados de indivíduos (Raup \& Stanley, 1978).

Muitas vezes, estes padrōes tornam-se obscuros e de difícil compreensão quando se leva em consideração a vasta extensão oceânica e a complexa interação dos fatores ambientais. Hoje, vários autores defendem a idéia de efetuar-se estudos contínuos e ordenados em áreas restritas (baías, enseadas), podendo assim caracterizar com maior precisāo estes padrōes.

Fatores do meio físico, como temperatura, salinidade, profundidade, teor de matéria orgânica e textura do substrato, parecem condicionar a distribuiçāo dos crustáceos decápodos, bem como de outros organismos marinhos bentônicos (Mackay, 1943; Thorson, 1957; Magliocca \& Kutner, 1964; Tommasi, 1967, 1970; Forneris, 1969; Abreu, 1975; Ishikawa, 1989). Merecem destaque alguns trabalhos que abordaram a distribuiçāo de algumas espécies de braquiúros, relacionando-os aos parâmetros ambientais: Holme (1949, 1954 e 1961), Sanders (1956 e 1958), Coelho \& Torres (1980), Gouveia \& Leite (1980), Stevens \& Armstrong (1984), PITA et al. (1985), Gouvea (1986a e 1986b), Buchanan \& Stoner (1988), Lewis \& Roer (1988), Moreira et al. (1988) e Branco et al. (1990).

Especificamente no litoral norte do Estado de São Paulo, pouco se conhece sobre a composição e padrōes distribucionais da fauna dos caranguejos. Neste sentido, o trabalho de Melo (1985) foi um impulso importante para desencadear uma série de trabalhos pioneiros realizados por Mantelatto (1991), Pinheiro (1991), Santos (1992) e Fransozo et al. (1992), todos na Enseada da Fortaleza, Ubatuba (SP). Um estudo mais amplo vem sendo desenvolvido por estes autores, abordando a fauna de braquiúros e anomuros da região.

O objetivo do presente trabalho é caracterizar a distribuiçāo espacial do caranguejo Hepatus pudibundus na Enseada da Fortaleza, Ubatuba (SP), enfocando o grau de associação com os fatores físicos e químicos registrados para a área em estudo.

\section{Material e métodos}

Os caranguejos foram coletados na Enseada da Fortaleza, Ubatuba (SP) $\left(23^{\circ} 31^{\prime} 00^{\prime \prime} \mathrm{S}\right.$ e $\left.45^{\circ} 09^{\prime} 00^{\prime \prime} \mathrm{W}\right)$, utilizando-se um barco de pesca equipado com duas redes do tipo "otter-trawl". As coletas foram realizadas mensalmente, pelo período de um ano (nov/1988 a out/1989). Cada coleta compreendeu 7 arrastos (radiais), de $1 \mathrm{~km}$ de extensão cada (Fig. 1). A área de coleta abrangida por cada arrasto foi denominada Radial.

Após o término do percurso de cada arrasto, as redes foram recolhidas e os caranguejos capturados foram ensacados, etiquetados e armazenados em freezer.

No ponto médio de cada radial (distante $500 \mathrm{~m}$ à partir do ponto inicial de cada arrasto), foram tomadas as amostras para a mensuração dos parâmetros hidrográficos, objetivando a análise dos fatores físico-químicos. A área de coleta das amostras (ponto médio) foi denominada de Estação. Toda a metodologia e os dados obtidos estão mencionados no trabalho de Negreiros-Fransozo et al. (1991).

Em laboratório, após prévio descongelamento à temperatura ambiente, procedeu-se a análise dos caranguejos, abordando os seguintes aspectos biológicos:

- Determinação do sexo;

- Contagem;

- Determinação da Maturaçāo Morfológica: jovens e adultos foram separados pelo formato e aderência do abdômen aos esternitos toracicos segundo Taissoun (1969) $\mathrm{e}$, posteriormente reunidos em quatro grupos de interesse (machos e fêmeas adultas, fêmeas ovígeras e jovens).

Visando determinar a associação dos fatores físicos e químicos registrados, com a quantidade de caranguejos obtidos em cada grupo de interesse, aplicou-se os testes da Análise de Correlaçāo Linear de Pearson, que segundo Ostle (1963) mede o grau de associaçāo (intensidade) entre variáveis observáveis 2 a 2, e a da Análise de Correlação Canônica.

As correlaçōes foram efetuadas entre o número de indivíduos obtidos em cada grupo de interesse e alguns fatores ambientais de maior importância (profundidade, temperatura, salinidade, oxigênio dissolvido e teor de matéria orgânica). $\mathrm{O}$ mesmo procedimento foi efetuado para cada uma das fraçōes granulométricas. Este tipo de análise vem sendo utilizada neste tipo de associação (Buchanan \& Stoner, 1988).

Embora tenha sido observada a variação sazonal de ocorrência em cada radial, todos os indivíduos coletados durante $o$ ano foram agrupados para as análises estatísticas. 


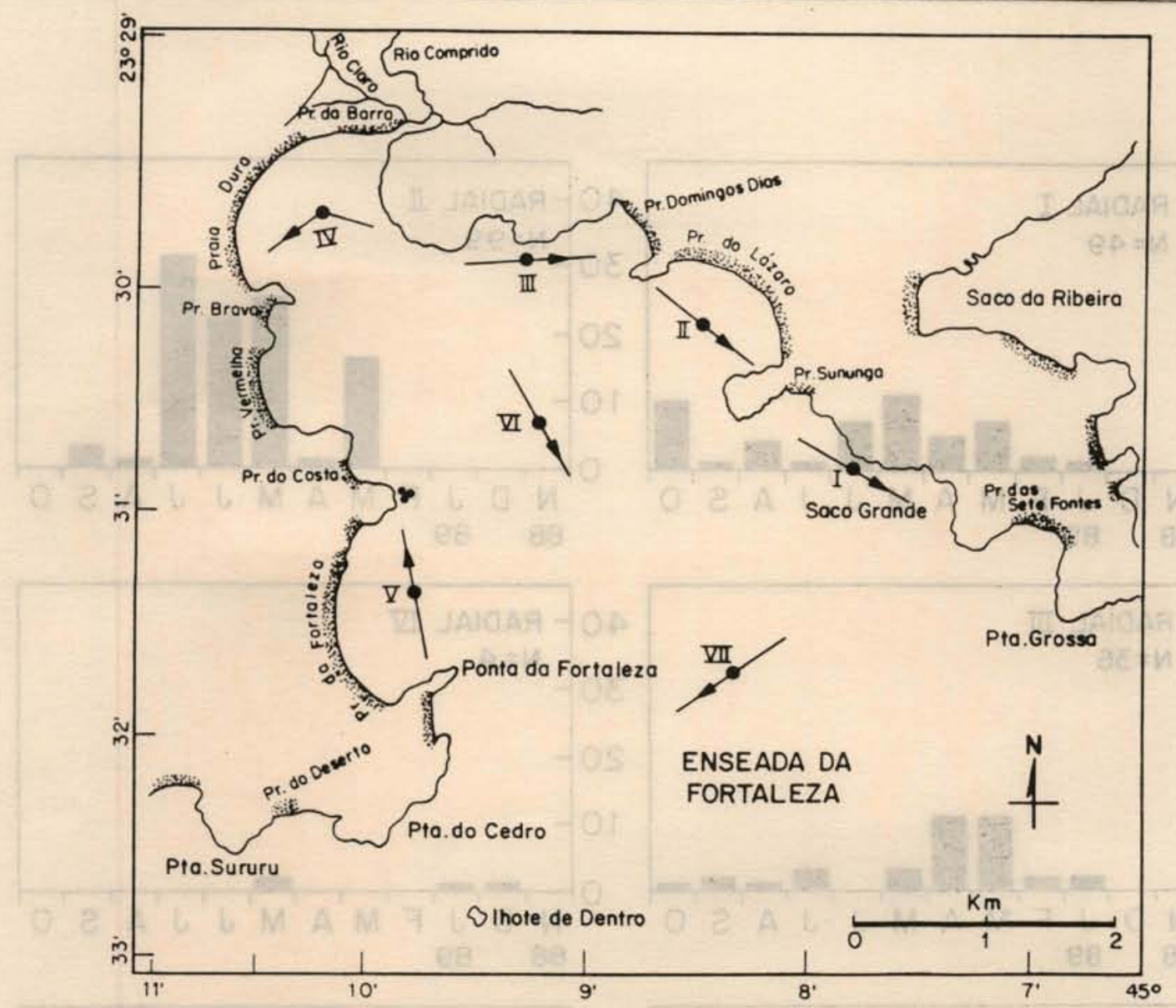

Fig. 1. Mapa da Enseada da Fortaleza, Ubatuba (SP), mostrando a localização das radiais e estações de coleta e a direção de cada arrasto.

\section{Resultados}

Durante todo o período de estudo foram realizadas 12 coletas, totalizando 84 arrastos em 7 radiais, obtendo-se 405 exemplares de $H$. pudibundus. Esta espécie apresentou-se distribuída em todas as radiais, observando-se a maior e a menor frequência de indivíduos nas radiais VII $(25,92 \%)$ e IV $(0,98 \%)$, respectivamente (Tab. 1).
Quanto à distribuição dos grupos de interesse, machos e fêmeas adultas e fêmeas ovígeras, todos apresentaram um padrāo semelhante ao observado para o total de indivíduos capturados. Somente os jovens apresentaram maior frequência de ocorrência na radial II (Tab. 1).

O número total de indivíduos coletados, em cada uma das radiais, ao longo do período de coleta, está evidenciado na Figura 2.

Tabela 1. Hepatus pudibundus. Número de indivíduos coletados nas 7 radiais da Enseada da Fortaleza, Ubatuba, SP. Os valores mostram o número total de indivíduos coletados e respectiva porcentagem em cada grupo de interesse.

\begin{tabular}{|c|c|c|c|c|c|c|c|c|c|c|}
\hline \multirow[t]{2}{*}{ Radiais } & \multirow[t]{2}{*}{ Machos } & \multirow[t]{2}{*}{ \% } & \multirow[t]{2}{*}{ Fêmeas } & \multirow[t]{2}{*}{ \% } & $\begin{array}{l}\text { Fêmeas } \\
\text { ovígeras }\end{array}$ & \multirow[t]{2}{*}{$\%$} & \multirow[t]{2}{*}{ Jovens } & \multirow[t]{2}{*}{$x$} & \multirow[t]{2}{*}{ Total } & \multirow[t]{2}{*}{$\%$} \\
\hline & & & & & & & & & & \\
\hline & & 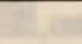 & 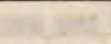 & & $=-1$ & 13 & $\operatorname{cotan}(7)$ & & & \\
\hline I & 24 & 5,93 & 20 & 4,94 & 2 & 0,49 & 3 & 0,74 & 49 & 12,10 \\
\hline II & 20 & 4,94 & 34 & 8,40 & ... & ... & 45 & 11,12 & 99 & 24,46 \\
\hline III & 17 & 4,20 & 13 & 2,95 & 1 & 0,25 & 5 & 1,48 & 36 & 8,88 \\
\hline IV & 2 & 0,48 & 1 & 0,25 & $\cdots$ & $\ldots$ & 1 & 0,25 & 4 & 0,98 \\
\hline v & 23 & 5,67 & 19 & 4,69 & 1 & 0,25 & 7 & 1,73 & 44 & 12,34 \\
\hline VI & 19 & 4,69 & 24 & 5,93 & 5 & 1,24 & 14 & 3,46 & 68 & 15,32 \\
\hline VII & 28 & 6,91 & 64 & 15,80 & 10 & 2,47 & 3 & 0,74 & 105 & 25,92 \\
\hline Total & 133 & & 175 & & 19 & & 78 & & 405 & \\
\hline
\end{tabular}



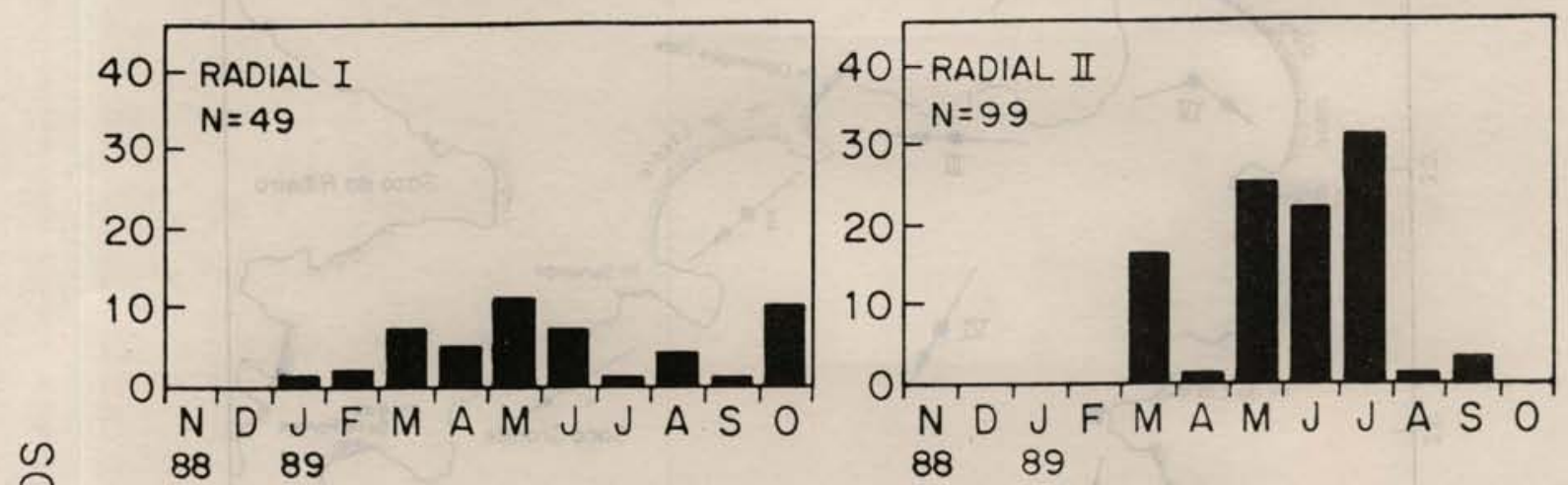

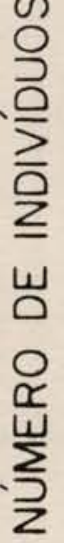
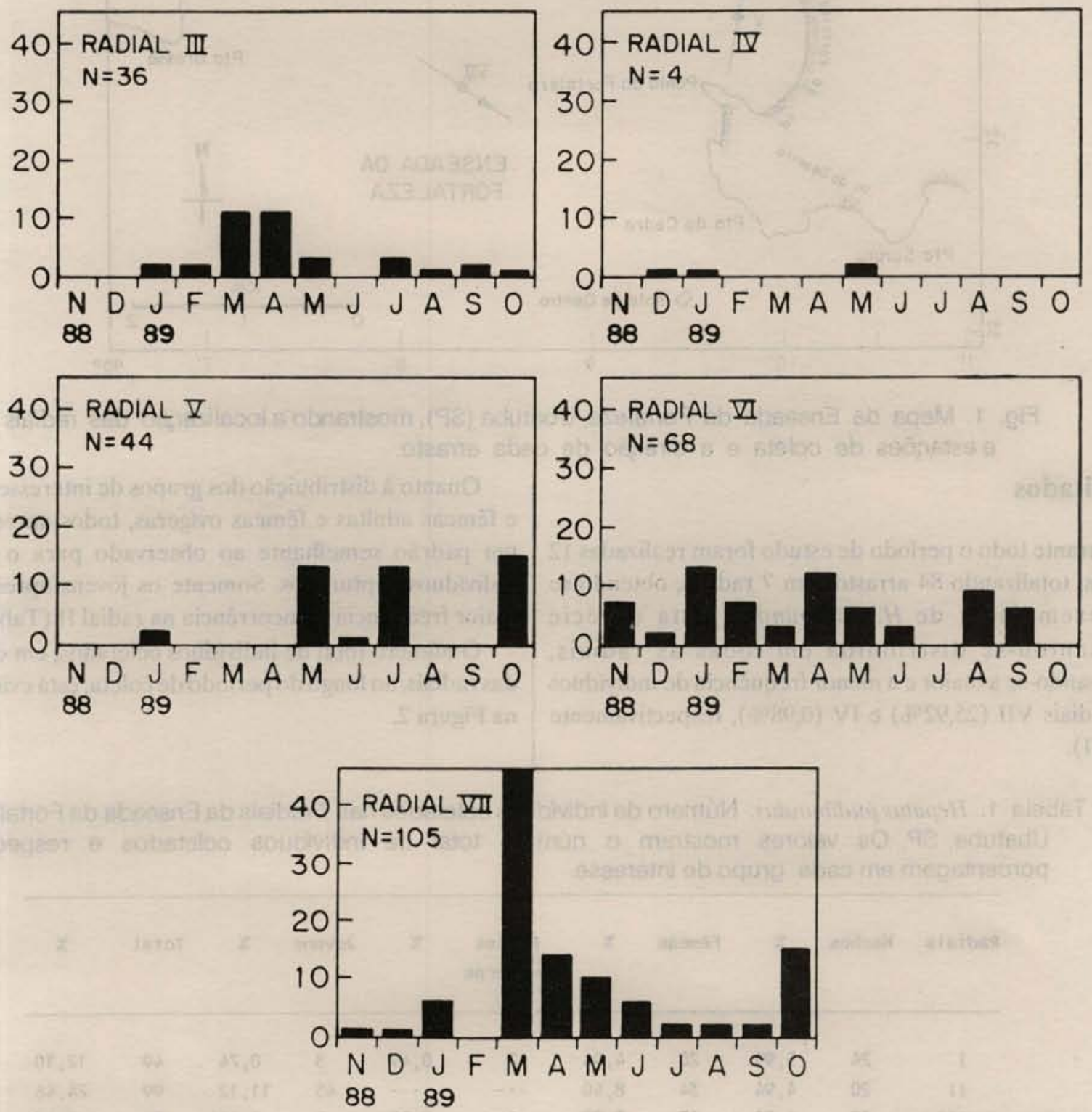

Fig. 2. H. pudibundus. Número total de indivíduos coletados em cada uma das radiais ao longo do período de coleta, na Enseada da Fortaleza, Ubatuba, SP. 
Na Tabela 2, encontra-se uma sinopse dos dados médios registrados para os fatores ambientais, a partir dos quais foram efetuadas as análises de correlação. Destas análises pode-se verificar diferentes graus de associação $e$ significância para cada fator abordado em relaçāo aos grupos de interesse (Tabs 3 e 4).

Os resultados referentes à associação entre os fatores físicos e químicos com a abundância de caranguejos, encontram-se registrados nas Tabelas 3 e 4.

$\mathrm{Na}$ Figura 3 encontram-se as distribuições dos números médios de indivíduos capturados por coleta, em cada classe dos fatores ambientais analisados. Quanto à matéria orgânica e à profundidade, observou-se um aumento no número médio de indivíduos por coleta à medida que ocorre um aumento gradativo destas variáveis. Com relaçāo ao teor de oxigênio, registrou-se uma diminuiçāo no número de indivíduos quando ocorre aumento nas taxas de oxigênio. Em relação à salinidade e temperatura não foi observado nenhum padrāo específico de distribuiçāo. Estes dados, principalmente teor de oxigênio e profundidade, corroboram os resultados obtidos nas análises de correlaçāo efetuadas.

\section{Discussão}

De modo geral, os resultados obtidos, referentes às condiçỏes ambientais (temperatura da água, oxigênio dissolvido, profundidade) na Enseada da Fortaleza, estiveram muito próximos aos registrados em estudos anteriores na região: Forneris (1969) na Enseada do Flamengo e Abreu (1975 e 1978) na própria Enseada da Fortaleza.

Os padrões de temperatura, salinidade e teor de oxigênio apresentaram-se homogêneos em relação às radiais, provavelmente devido à intensa circulaçāo das massas de água vindas da Plataforma Continental.

De acordo com Vernberg \& Vernberg (1970) fatores ambientais que apresentam uma variação mais acentuada em determinada área, são notoriamente considerados como os principais agentes limitantes à distribuiçāo.

Particularmente para as espécies bentônicas, vários trabalhos têm considerado a textura do sedimento e o seu conteúdo orgânico como os principais fatores determinantes da distribuiçāo (Tommasi, 1967; Amaral, 1980; Monteiro, 1987 e Ishikawa, 1989).

Tabela 2. Valores médios dos fatores ambientais da Enseada da Fortaleza, Ubatuba, SP, baseados nos 12 meses de coleta (nov/88 a out/89), exceto para o sedimento, onde são mencionadas as frações predominantes e suas respectivas porcentagens em cada estação

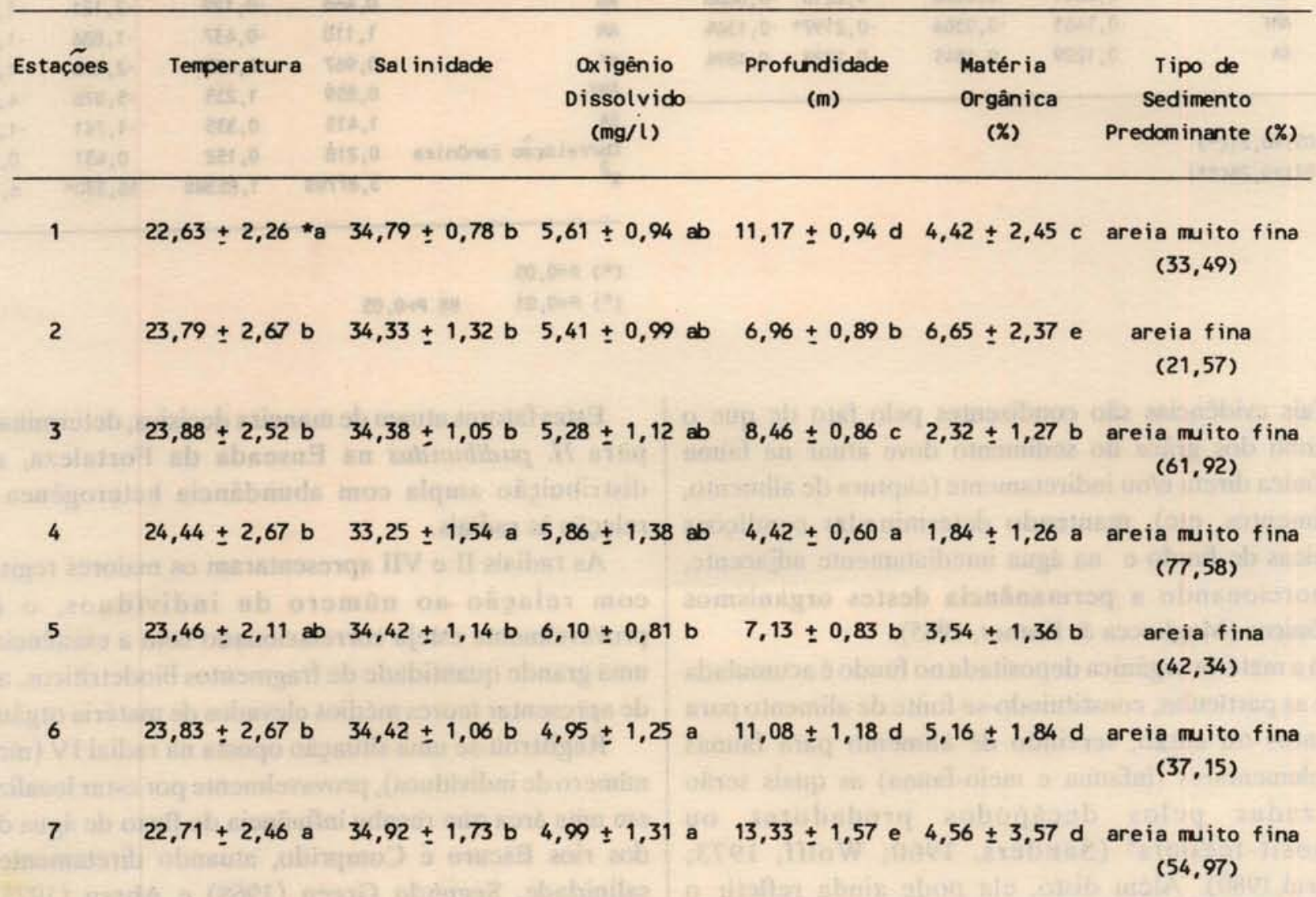

(*) as médias seguidas de pelo menos uma mesma letra na coluna, não diferem entre si quanto à variável ambiental anal isada 
Tabela 3. Hepatus pudibundus. Coeficiente de Correlação Linear de Pearson entre a abundância absoluta de indivíduos coletados e alguns fatores ambientais para cada grupo de interesse. $(C=$ cascalho; $A M G=$ areia muito grossa; $A G=$ areia grossa; $A M=$ areia média; $\mathrm{AF}=$ areia fina; $\mathrm{AMF}=$ areia muito fina; $\mathrm{SA}=$ silte + argila), $M A=$ machos adultos; $F A=$ Fêmeas adultas; $\mathrm{J}=$ jovens; $\mathrm{TO}=$ total). $\mathrm{N}=$ 84.

\begin{tabular}{|c|c|c|c|c|}
\hline $\begin{array}{l}\text { Conjunto de } \\
\text { Var iavé is }\end{array}$ & ma & FA & J & то \\
\hline Profundidade & 0,1961 & $0,3373 \approx$ & $-0,1187$ & $0,2151^{*}$ \\
\hline Temperatura & 0,0045 & 0,1165 & 0,0474 & 0,0845 \\
\hline Sal inidade & $-0,0307$ & 0,0295 & $-0,0012$ & 0,0075 \\
\hline Oxigênio dissolvido & $-0,3242 *$ & $-0,3566$ ** & $-0,0941$ & $-0,3344 *$ \\
\hline Matéria orgảnica & 0,0915 & $-0,0025$ & 0,0527 & 0,0665 \\
\hline Tipo de sedimento & MA & FA & J & то \\
\hline c & $-0,0332$ & $-0,0386$ & 0,2201 * & 0,0460 \\
\hline AMG & $-0,0411$ & $-0,0568$ & 0,1691 & 0,0275 \\
\hline AG & 0,0473 & $-0,0138$ & 0,0365 & 0,0204 \\
\hline AM & 0,0748 & $-0,0164$ & 0,0613 & 0,0302 \\
\hline AF & 0,0631 & $-0,0246$ & 0,0210 & $-0,0066$ \\
\hline AMF & $-0,1463$ & $-0,0366$ & $-0,2197$ & $-0,1364$ \\
\hline SA & 0,1229 & 0,1345 & 0,1928 & 0,1894 \\
\hline
\end{tabular}

$r(0,05)>0,21\left(^{*}\right)$

$r(0,01)>0,28(*)$
Tabela 4. Hepatus pudibundus. Coeficiente de Correlação Canônica entre a abundância absoluta de indivíduos coletados e alguns fatores ambientais para cada grupo de interesse. $(C=$ cascalho; $A M G=$ areia muito grossa; $A G=$ areia grossa; $A M=$ areia média; $\mathrm{AF}=$ areia fina; $\mathrm{AMF}=$ areia muito fina; $\mathrm{SA}$ $=$ silte + argila), $M A=$ machos adultos; $F A$ $=$ Fêmeas adultas; $\mathrm{J}=$ jovens; $\mathrm{TO}=$ total). $\mathrm{N}$ $=84$.

\begin{tabular}{|c|c|c|c|c|}
\hline $\begin{array}{l}\text { Conjunto de } \\
\text { Variavéis }\end{array}$ & $M A$ & FA & J & TO \\
\hline & & & & \\
\hline Profundidade & 0,430 & 0,727 & $-0,916$ & 0,463 \\
\hline Temperatura & $-0,146$ & 0,200 & 0,261 & 0,159 \\
\hline Sal inidade & $-0,445$ & $-0,258$ & 0,397 & $-0,224$ \\
\hline Oxigènio dissolvido & $-0,863$ & $-0,621$ & $-0,597$ & $-0,811$ \\
\hline Matéria orgânica & 0,146 & $-0,115$ & 0,613 & 0,140 \\
\hline Correlacão canônica & 0,391 & 0,483 & 0,209 & 0,392 \\
\hline
\end{tabular}

\begin{tabular}{lrrrr} 
Tipo de sedimento & MA & FA & J & TO \\
\hline & & & & \\
C & 0,394 & 0,206 & $-0,227$ & $-0,216$ \\
AMG & $-0,412$ & $-0,875$ & $-0,554$ & $-0,604$ \\
AG & 0,466 & $-0,129$ & $-2,121$ & $-1,537$ \\
AM & 1,110 & $-0,437$ & $-1,886$ & $-1,609$ \\
AF & 0,967 & $-0,437$ & $-2,176$ & $-1,839$ \\
AMF & 0,859 & 1,235 & $-5,076$ & $-4,598$ \\
SA & 1,415 & 0,335 & $-1,741$ & $-1,379$ \\
Correlaça canónica & 0,218 & 0,152 & 0,431 & 0,272 \\
X $^{2}$ & $3,877 N S$ & $1,853 N S$ & $16,330 *$ & $6,104 N S$ \\
& & & & \\
\hline
\end{tabular}

(*) $P<0,05$

(*) $P<0,01 \quad$ NS $P>0,05$

Estes fatores atuam de maneira decisiva, determinando para $H$. pudibundus na Enseada da Fortaleza, uma distribuiçāo ampla com abundância heterogênea em relação às radiais.

As radiais II e VII apresentaram os maiores registros com relação ao número de indivíduos, o que provavelmente esteja correlacionado com a existência de uma grande quantidade de fragmentos biodetríticos, além de apresentar teores médios elevados de matéria orgânica.

Registrou-se uma situação oposta na radial IV (menor número de indivíduos), provavelmente por estar localizada em uma área que recebe influência do fluxo de água doce dos rios Escuro e Comprido, atuando diretamente na salinidade. Segundo Green (1968) e Abreu (1975), a salinidade e o sedimento são limitantes na distribuição de certas espécies de Decapoda. 


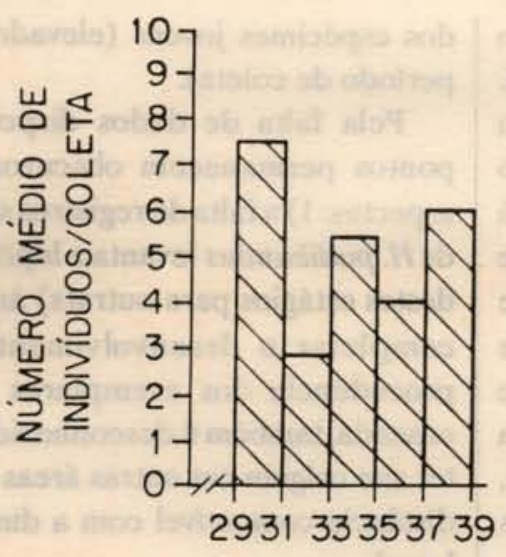

SALINIDADE (\%०)

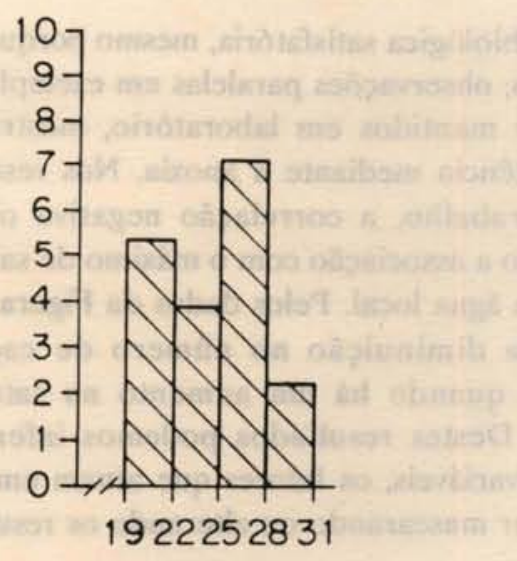

TEMPERATURA $\left({ }^{\circ} \mathrm{C}\right)$

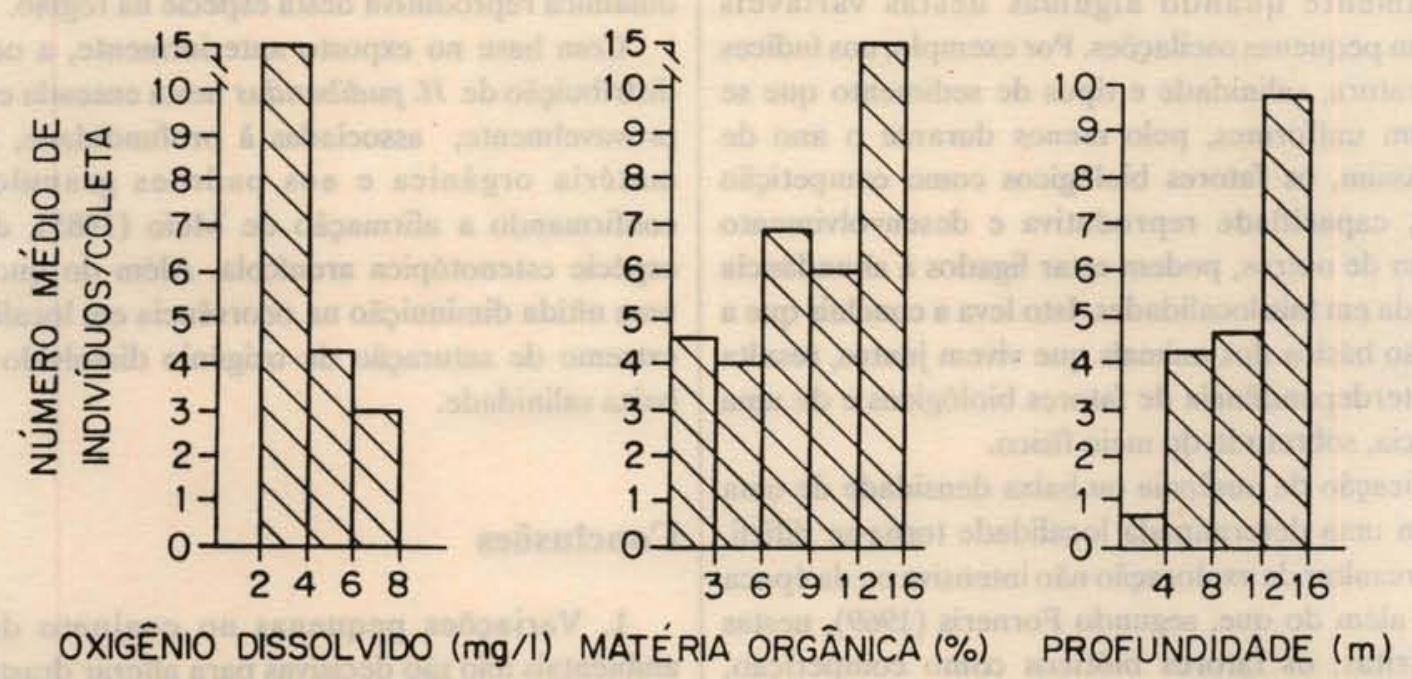

Fig. 3. H. pudibundus. Número médio de indivíduos coletados em cada uma das classes de valores dos fatores físico-químicos analisados, na Enseada da Fortaleza, Ubatuba, SP.

Este fluxo pode ainda promover uma "lavagem" do sedimento, deslocando os componentes da matéria orgânica para outro local, provavelmente a maior parte, para a radial VI.

Considerando-se os resultados da distribuição dos indivíduos em relação às classes de fatores abióticos, parece claro que somente variaçōes pequenas, nestes fatores, nāo são decisivas para alterar totalmente o padrão de distribuição desta espécie.

Com relação aos grupos de interesse abordados, nota-se que o comportamento distribucional em todos eles é semelhante ao que ocorre com o total de indivíduos. No entanto, verifica-se que indivíduos jovens e fêmeas têm uma nítida preferência pelas radiais II e VII, respectivamente, onde se registraram os maiores índices de matéria orgânica e profundidade.

Os parâmetros acima abordados sāo reforçados quando se analisa a Tabela 3 , onde é registrada uma correlação positiva entre jovens e o cascalho $(0,22)$ : A correlação positiva $(0,33)$ ocorrida entre fêmeas adultas e profundidade, foi também registrada para o total $(0,21)$.

Da análise da Correlação Canônica (Tab. 4) podemos concluir que para machos e fêmeas adultas e total de indivíduos, cujos valores foram significativos, o conjunto das variáveis analisadas é que está influenciando a distribuição, principalmente para fêmeas adultas $(21,34)$. Isto nos leva a crer que a distribuição destes indivíduos tende a ser influenciada pelo conjunto dos fatores abióticos analisados e que um deles pode exercer maior ou menor força no hábito geral, como por exemplo, a forte influência da profundidade na distribuição das fêmeas. Em relação às variáveis granulométricas, parece que apenas os indivíduos jovens tiveram sua distribuição influenciada pelo tipo de fraçāo granulométrica $(16,33)$.

Quanto às correlaçōes negativas obtidas (Tab.3), como por exemplo entre os grupos de interesse e oxigênio dissolvido, deve-se ter cautela. Provavelmente, este e outros dados matemáticos obtidos não tenham uma 
explicaçāo biológica satisfatória, mesmo porque, no caso do oxigênio, observaçōes paralelas em exemplares de $H$. pudibundus mantidos em laboratório, mostraram uma baixa resistência mediante à anoxia. Nos resultados do presente trabalho, a correlação negativa obtida está expressando a associação com o máximo de saturaçāo de oxigênio na água local. Pelos dados da Figura 3, nota-se uma nítida diminuição no número de capturas de indivíduos quando há um aumento na saturaçāo de oxigênio. Destes resultados podemos inferir que na análise de variáveis, os fatores que atuam em conjunto, podem estar mascarando ou alterando os resultados das correlaçōes.

A presença de algumas espécies em certas localidades não é determinada unicamente por fatores ambientais, principalmente quandó algumas destas variáveis apresentam pequenas oscilaçōes. Por exemplo, nos índices de temperatura, salinidade e tipos de sedimento que se mantiveram uniformes, pelo menos durante o ano de coleta. Assim, os fatores biológicos como competiçāo alimentar, capacidade reprodutiva e desenvolvimento larval, além de outros, podem estar ligados à abundância diferenciada em tais localidades. Isto leva a concluir que a organização básica dos animais que vivem juntos, resulta de uma interdependência de fatores biológicos e de uma dependência, sobretudo do meio físico.

A explicação da ausência ou baixa densidade de uma espécie em uma determinada localidade torna-se difícil, pois pode resultar da exploraçāo nāo intensiva ou da época de coleta, além do que, segundo Forneris (1969), nestas áreas restritas, os fatores bióticos como competição, predação, entre outros, podem exercer papéis decisivos na distribuiçāo de organismos bentônicos.

Uma espécie dificilmente está distribuída homogeneamente em sua área de ocorrência, pois poderá haver deslocamentos, conforme as condiçōes ambientais ou mesmo devido às diferentes exigências, durante as diversas fases da vida. Este fato é confirmado por VANIN (1989) sobre a existência de diferenças quantitativas na distribuição da megafauna bêntica de Ubatuba (SP). Para H. pudibundus tais exigências podem levar a modificaçōes na estrutura da populaçāo (Mantelatto et al., 1995), além de proporcionar padrōes diferenciados de engorda (Mantelatto \& Fransozo, 1992)

Segundo Fransozo et al. (1992), H. pudibundus ocupou o segundo lugar quanto ao número de indivíduos entre os Brachyura da Enseada da Fortaleza. Abundância relevante foi observada no presente estudo, o que nos leva a inferir que esta enseada é uma área que reúne condiçōes favoráveis à permanência desta espécie, seja quanto à procriação (elevado número de fêmeas com ovos em diferentes estágios de maturação; machos e fêmeas aptos ao processo reprodutivo) ou quanto ao desenvolvimento dos espécimes jovens (elevado recrutamento durante o período de coleta).

Pela falta de dados disponíveis na literatura, dois pontos permanecem obscuros para elucidaçāo destes aspectos: 1) a falta de registros sobre a ocorrência de larvas de $H$. pudibundus levanta a hipótese sobre o deslocamento destes estágios para outra(s) área(s), com a finalidade de completar o desenvolvimento larval e juvenil; 2) a procedência dos exemplares jovens, recrutados nesta enseada, também é desconhecida. Estes indivíduos podem ter sua origem em outras áreas de reprodução, situadas à distância compatível com a duraçāo do desenvolvimento larval.

Desta forma, estudos futuros nestes aspectos, poderảo auxiliar muito no entendimento sobre a ocupação e a dinâmica reprodutiva desta espécie na regiāo.

Com base no exposto anteriormente, a ocorrência e distribuiçāo de $H$. pudibundus nesta enseada estão, muito provavelmente, associadas à profundidade, ao teor de matéria orgânica e aos padrōes granulométricos, confirmando a afirmação de Melo (1985), de ser uma espécie estenotópica arenícola. Além do que apresenta uma nítida diminuição na ocorrência em localidades com extremo de saturação de oxigênio dissolvido na água e baixa salinidade.

\section{Conclusões}

1. Variaçōes pequenas no conjunto dos fatores ambientais nāo sāo decisivas para alterar drasticamente o padrāo de distribuição de $H$. pudibundus.

2. Indivíduos jovens apresentaram uma nítida preferência por radiais onde se registraram os maiores índices de matéria orgânica e profundidade.

3. Para os grupos de interesse: machos e fêmeas adultas e o total de indivíduos, a análise de correlaçāo efetuada, evidenciou uma distribuição fortemente influenciada pelo conjunto de variáveis abióticas e nāo por uma única variável isolada.

4. A distribuição diferenciada, observada para cada grupo de interesse abordado, provavelmente está regida por uma combinação de alguns fatores abióticos, que estariam proporcionando condiçōes limitantes à ocupaçāo em determinadas radiais, como por exemplo, matéria orgânica com sedimento, salinidade e textura do sedimento, profundidade e temperatura.

5. Fatores biológicos, nâo analisados, como competição alimentar, capacidade reprodutiva, desenvolvimento larval, deslocamentos sazonais e exigências nutricionais, devem estar contribuindo para a determinaçāo do padrāo de distribuição apresentado pela espécie.

6. Apesar da textura do sedimento não ter apresentado uma alta correlação com a abundância dos indivíduos, esta 
é, sem dúvida, uma variável importantíssima, cuja correlação pode ter sido mascarada por outras variáveis. Tal afirmaçāo é embasada no hábito contante desta espécie de se enterrar (que pode ser facilitado ou dificultado em funçāo da compactaçāo do sedimento), apresentando morfologia adaptada para tal, principalmente para proporcionar um eficiente mecanismo de circulação da água junto às brânquias quando o animal encontrar-se enterrado.

\section{Agradecimentos}

Ao Conselho Nacional de Desenvolvimento Científico e Tecnológico ( $\mathrm{CNPq})$, à Fundação para o Desenvolvimento da UNESP (FUNDUNESP) pelo suporte financeiro para o trabalho e aos membros do NEBECC no auxílio dos trabalhos de campo e laboratório.

\section{Referências bibliográficas}

ABREU, J. 1975. Distribuiçâao e ecologia dos Decapoda numa área estuarina de Ubatuba (SP). Dissertaçāo de mestrado. Universidade de São Paulo, Instituto Oceanográfico. 78p.

1978. Ecologia e distribuição dos Polichaeta e Mollusca na Enseada da Fortaleza (Ubatuba, Estado de São Paulo). Tese de doutorado. Universidade de São Paulo, Instituto Oceanográfico. 123 p.

AB'SABER, A. N. 1955. Contribuição à geomorfologia do litoral paulista. Rev. bras. Geogr., Sāo Paulo, 1:1-37.

AMARAL, A. C. Z. 1980. Anelídeos polichaetos do infralitoral em duas enseadas da região de Ubatuba. 1. Características abióticas das enseadas. Bolm Inst. oceanogr., S Paulo, 29(1):19-40.

BRANCO, J. O.; PORTO-FILHO, E. \& THIVES, A. 1990. Estrutura das populaçōes, abundância e distribuição dentro de espécies integrantes da família Portunidae (Crustacea, Decapoda) da Lagoa da Conceição e área adjacente, Illha de Santa Catarina, SC, Brasil. In: ANAIS DO II SIMPÓSIO DE ECOSSISTEMAS DA COSTA SUL E SUDESTE BRASILEIRA. Anais. 2., Sāo Paulo, Águas de Lindóia, 1990. São Paulo, ACIESP, p.294-300.
BUCHANAN, B. A. \& STONER, A. W. 1988. Distributional patterns of blue crabs (Callinectes sp) in a tropical Estuarine Lagoon. Estuaries, Lawrence, 11:231-239.

COELho, P. A. \& TORRES, M. F. A. 1980. Zoogeografia marinha do Brasil. II. Consideraçōes ecológicas e biogeográficas sobre a família Leucosiidae (Decapoda: Brachyura). Rev. Nordest. Biol., João Pessoa, 3(ESPECIAL):67-77.

FORNERIS, L. 1969. Fauna bentônica da Baía do Flamengo, Ubatuba, SP: aspectos ecológicos. Tese de livre-docência. Universidade de São Paulo, Instituto de Biociências. 215 p.

FRANSOZO, A.; NEGREIROS-FRANSOZO, M. L; MANTELATTO, F. L. M.; PINHEIRO, M. A. A. \& SANTOS, S. 1992. Composiçāo e distribuição dos Brachyura (Crustácea, Decapoda) no sublitoral não consolidado na Enseada da Fortaleza, Ubatuba, SP. Rev. bras. Biol., Rio de Janeiro, 52(4):667-675.

GOUVEA, E. P. 1986a. A carcinofauna do litoral rochoso de Salvador, BA, e alguns aspectos ecológicos. Ciência Cult., São Paulo, 38(2):346-355.

1986b. A carcinofauna do litoral arenoso e areno- lodoso de Salvador, BA e áreas adjacentes. Ciência Cult., São Paulo, 38(5):875-883.

\& LEITE, Y. M. 1980. A carcinofauna do fital da Halimeda opuntia (Linnaeus) Lamouroux e a variação sazonal de sua densidade. Ciência Cult., São Paulo, 32(5):596-600.

GREEN, J. 1968. The biology of estuarine animals. London, Sidgwick \& Jackson, 401p.

HOLME, N. A. 1949. The fauna of sand and mud banks near the mouth of the Exe Estuary. J. mar. biol. Assoc. U. K., Cambridge, 28:184-237

1954. The ecology of British species of Ensis. J. mar. biol. Assoc. U. K., Cambridge, 33:145-172.

1961. The bottom fauna of the English channel. J. mar. biol. Assoc. U. K., Cambridge, 41:397-461. 
ISHIKAWA, K. 1989. Relationship between bottom characteristics and benthic organisms in the shallow water of Oppa Bay, Miyagi. Mar. Biol., Berlim, 102:265-273.

LEWIS, D. H. \& ROER, R. D. 1988. Thermal preference in distribution of blue crabs, Callinectes sapidus in a power plant cooling pond. J. crustacean Biol., San Antonio, 8(2):283-289.

MACKAY, D. G. 1943. Temperature and the world distribution of crabs of the genus Cancer. Ecology, Tempe, 24(11):113-115.

MAGLIOCCA, A. \& KUTNER, A. S. 1964. Conteúdo orgânico dos sedimentos de fundo de Cananéia, São Paulo. Contrçōes Inst. Oceanogr., São Paulo, (7):1-14.

\& 1965.

Sedimentos de fundo da Enseada do Flamengo, Ubatuba, SP. Contrçōes Inst. Oceanogr., São Paulo, (8):1-15.

MANTELATTO, F. L. M. 1991. Distribuição e crescimento relativo de Hepatus pudibundus (Herbst, 1785) (Crustacea, Decapoda, Brachyura) na Enseada da Fortaleza, Ubatuba, SP. Dissertação de mestrado. UNESP, Botucatu, Instituto de Biociências. 138 p.

\& FRANSOZO, A. 1992. Relação Peso/Largura da carapaga no caranguejo Hepatus pudibundus (Herbst, 1785) (Crustacea, Decapoda, Calappidae) na regiāo de Ubatuba, SP, Brasil. Arq. Biol. Tecnol., Curitiba, 35(4):719-724.

\&

NEGREIROS-FRANSOZO, M. L. 1995. Populational structure of Hepatus pudibundus (Herbst, 1785) (Decapoda, Brachyura, Calappidae) in Fortaleza Bay, Ubatuba (SP), Brazil. Revta. Biol. trop., Costa Rica, 43(1):259-264.

MELO, G. A. S. 1985. Taxonomia e padrões distribucionais e ecológicos dos Brachyura (Crustacea, Decapoda) do litoral sudeste do Brasil. Tese de doutorado. Universidade de São Paulo, Instituto de Biociências. 215 p.
MONTEIRO, A. M. G. 1987. Ophiuroidea (Echinodermata) da regiāo de Ubatuba (SP) Aspectos morfológicos e ecológicos. Tese de doutorado. Universidade de São Paulo, Instituto Oceanográfico. $171 \mathrm{p}$.

MOREIRA, P. S.; PAIVA FILHO, A. M.; OKIDA, C. M.; SCHMIEGELOW, M. M. \& GIANINI, R. 1988. Bioecologia de crustáceos decápodos, braquiúros no sistema baía-estuário de Santos e São Vicente, SP. I. Ocorrência e composição. Bolm Inst. oceanogr., S Paulo, 36(1/2):55-62.

NEGREIROS-FRANSOZO, M. L.; FRANSOZO, A.; PINHEIRO, M.A. A.; MANTELATTO, F. L. M. \& SANTOS, S. 1991. Caracterização física e química da Enseada da Fortaleza, Ubatuba (SP). Rev. bras. Geol., São Paulo, 21(2):114-120.

OSTLE, B. 1963. Statistics in research. Ames: The Iowa State University Press. 2 ed., cap. IX. Correlation analyses. p.222-243.

PINHEIRO, M. A. A. 1991. Distribuição e biologia populacional de Arenaeus cribrarius (Lamarck, 1818) (Crustacea, Decapoda, Portunidae) na Enseada da Fortaleza, Ubatuba, SP. Dissertação de mestrado.UNESP, Campus de Botucatu, Instituto de Biociências. 175p.

PIRES-VANIN, A. M. S. 1989. Estrutura e dinâmica da megafauna bêntica na Plataforma Continental da Região Norte do estado de São Paulo, Brasil. Tese de livre-docência. Universidade de São Paulo, Instituto Oceanográfico.172 p.

PITA, J. B.; RODRIGUES, E. S.; GRAGA LOPEZ, R. \& COELHO, J. P. A. 1985. Observaçōes bioecológicas sobre o siri Callinectes danae Smith, 1869 (Crustacea, Decapoda, Portunidae) no complexo Baía-Estuário de Santos, SP, Brasil. Bolm Inst. Pesca, São Paulo, 12(4):35- 43.

RAUP, D. M. \& STANLEY, S. M. 1978. Paleoecology. In: Principles of Paleontology. $2^{\mathrm{a}}$ ed. São Francisco, Freeman and CO. Ed., p. 231-299.

SANDERS, H. L. 1956. Oceanography of Long Island Sound 1952 - 1954. X. The biology of marine bottom communities. Bull. Bingham. oceanogr. Colln, New Haven, 15:344-414. 
SANDERS, H. L. 1958. Benthic studies in Burzards Bay. 1. Animal sediment relationships. Limnol. Oceanogr., Grafton, 3:245-258.

1960. Benthic studies in Burzards Bay.

3. The structure of the softbothom community. Limnol. Oceanogr., Grafton, 5:138-153.

SANTOS, S. 1992. Biologia de Portunus spinimanus Latreille, 1819 (Crustacea, Brachyura, Portunidae) na Enseada da Fortaleza, Ubatuba (SP). Dissertaçāo de mestrado. UNESP, Campus Botucatu, Instituto de Biociências. 108 p.

STEVENS, B. G. \& ARMSTRONG, D. A. 1984. Distribution, abundance and growth of juvenile dugness crab Cancer magister, in Grays Harbor Estuary, Washington. Fish. Bull., Dublin, 82(3): 469483.

SUGUIO, K. \& MARTIN, L. 1978. Formaçōes quaternárias marinhas do litoral paulista e fluminense. In: INTERNATIONAL SYMPOSIUM ON COASTAL EVOLUTION IN THE QUATERNARY. Sāo Paulo, Sociedade Brasileira de Geologia, Especial Publicação, (1):1-55.

TAISSOUN, E. N. 1969. Las especies de cangrejos del genero Callinectes (Brachyura) en el Golfo de Venezuela y Lago de Maracaibo. Bol. Centro Invest. Biol., Maracaibo, 2:1-101.
THORSON, G. 1957. Bottom communities (sublitoral on shallow-shelf). Bull. geol. Soc. Am., Boulder, 67:461-534.

TOMMASI, L. R. 1967. Observaçōes preliminares sobre a fauna bêntica de sedimentos moles da baía de Santos e regiōes vizinhas. Bolm Inst. oceanogr., S Paulo, 16(1):43-65.

1970. Observaçōes sobre a fauna bêntica do complexo estuarino-lagunar de Cananéia, SP. Bolm Inst. oceanogr., Sāo Paulo, 19:43-56.

VERNBERG, F. J. \& VERNBERG, W. B. 1970. Lethal limits and zoogeography of the faunal assemblages of coastal Carolina waters. Mar. Biol., Berlim, 6:26-32.

WOLFF, W. J. 1973. The Estuary as a habitat an analysis of data on soft bottom macrofauna of the estuarine area of the Rivers Rhine, Meuse and Scheldt. Zool. verh., Leiden, 126:1-242.

(Manuscrito recebido 19 outubro 1993; revisto 12 maio 1995; aceito 09 junho 1995) 